\title{
EFFECT OF EYES OPEN AND BLINDFOLD ON GENDER AND HANDEDNESS USING MOBERG PICKUP TEST- A COMPARATIVE STUDY
}

\author{
Narayan V. Kamat Dalal ${ }^{1}$, Sanjay S. Pandarbale ${ }^{2}$, S. R. Sardessai ${ }^{3}$ \\ ${ }_{1}^{1}$ Assistant Lecturer, Department of Physiology, Goa Medical College, Bambolim, Goa, India. \\ ${ }^{2}$ Associate Professor, Department of Physiology, Goa Medical College, Bambolim, Goa, India. \\ 3Professor and HOD, Department of Physiology, Goa Medical College, Bambolim, Goa, India.
}

\section{ABSTRACT}

\section{BACKGROUND}

Moberg defined hand function as precision sensory grip. Whenever a precision sensory grip is possible, protective sensation is always present.

\section{MATERIALS AND METHODS}

Moberg pickup test was conducted in 150 apparently healthy first year medical students comprising of 86 females and 64 males between age group of 18-21 years. Twelve commonly used metallic objects were chosen. The present study aims to see the impact of eyes open and blindfolded on gender and handedness using Moberg pickup test in medical students.

\section{RESULTS}

Data was collected using purposive sampling technique and was scientifically analysed using student $\mathrm{t}$ test and $\mathrm{p}$ value of $<0.05$ and $<0.001$ was considered as significant and highly significant respectively. It was observed that dominant hand performed the test faster than non-dominant hand with eyes open and when blindfolded. Males were found to be faster than females while performing the test using both dominant and non-dominant hand with eyes open and when blindfolded.

\section{CONCLUSION}

Moberg pickup test being simple, convenient and cheaper can widely be applied to assess hand coordination and also as an assessment tool for recovery of hand functions following injury.

\section{KEYWORDS}

Moberg Pickup Test, Dominant Hand, Non-dominant Hand, Blindfolded, Medical Students.

HOW TO CITE THIS ARTICLE: Dalal NVK, Pandarbale SS, Sardessai SR. Effect of eyes open and blindfold on gender and handedness using Moberg pickup test- A comparative study. J. Evolution Med. Dent. Sci. 2017;6(30):2419-2421, D0I: $10.14260 /$ Jemds/2017/522

\section{BACKGROUND}

We all know that human hand is a wonder. Four fingers and an opposable thumb work together to enable humans to interact with each other and shape the world around them which is a unique feature in humans. Fingertips have highest concentration of touch receptors. These dense areas of nerve endings makes the fingers extremely sensitive to heat, cold, pressure, vibration, texture, and moisture.(1)

As per the studies in the past it was seen that somatosensory input is considered as one of the important determinants of motor performance executed by the upper limbs.(2-4) In particular, the fingertips are dependent primarily on tactile afferents for sensory information to distinguish the object shape, mass, mass distribution, and the friction of the grasp that is necessary for fine motor control.(3)

\section{Financial or Other, Competing Interest: None.}

Submission 06-03-2017, Peer Review 26-03-2017,

Acceptance 05-04-2017, Published 13-04-2017.

Corresponding Author:

Dr. Narayan V. Kamat Dalal,

Assistant Lecturer,

Department of Physiology,

Goa Medical College,

Bambolim,

Goa.

E-mail: nvkd10@gmail.com

DOI: $10.14260 /$ jemds $/ 2017 / 522$

\section{(c) (i) $(9)$}

Studies in the past have also shown that any disruption of sensations at the tips of the fingers can compromise fine motor dexterity of the hand.(5)

In 1958, Eric Moberg developed a test to quantify the ability of the hand.(6) The present study was conducted with the aim to study the effect of eyes open and blindfolded on gender and handedness using Moberg pickup test in medical students. We also hypothesised that dominant hand is more skilled in task performance than the non-dominant hand.

\section{MATERIALS AND METHODS}

Moberg pickup test was conducted in 150 healthy first year medical students of age group of 18-21 years in Department of Physiology, Goa Medical College and Hospital, Bambolim, Goa.

Inclusion criteria was willingness to participate in the study and those who gave consent to perform the test. Exclusion criteria included that the students did not suffer from any deformity of upper extremities, nor any subjective sensory or motor complaints in the upper extremities such as numbness, tingling, and weakness, peripheral neuropathy nor on any treatment for chronic illnesses, on cough sedatives, less than six hours of sleep, alcohol intake.

Twelve commonly used metallic objects like rectangular battery, nut, bolt, lock, bottle cap, screw, circular weight, valve, window latch, door knob, nose clip, laser pointer were spread randomly on a wooden platform of dimension $52 \times 30$ x $2.5 \mathrm{~cm}$ and a circular container 6 inch in diameter was 
placed at one side of wooden platform (figure 1). Subjects were made to sit comfortably in front of a wooden platform that was placed on a table lengthwise. The platform was used so that the metallic objects could be placed well within the defined limits and a uniformity be maintained throughout the study. Test metallic objects were all placed on the platform on the same side as the hand being tested first, whereas the container was placed on the opposite side of the hand to be tested.

Subjects were instructed to start picking up the objects one at a time by only using their thumb, index and middle finger and not to slide the objects on the platform while performing the task and place them into the circular container as fast as possible. Their performance was timed with a stopwatch.

This test was conducted in two phases- (1) With eyes open and (2) Blindfolded. For each phase of the test, dominant hand, defined as the one used for writing, was tested first followed by the non-dominant hand.(7) Subjects were instructed to perform the test three times each for dominant and non-dominant hand to obtain an average. The instructions to perform the two phases of the test were identical but when blindfolded, subjects were instructed to hold the circular container with the opposite hand and when only four objects were left on the platform they were told about the number of items left on the platform; this avoided the tendency of the subject to count the objects and thus getting distracted while performing the task.

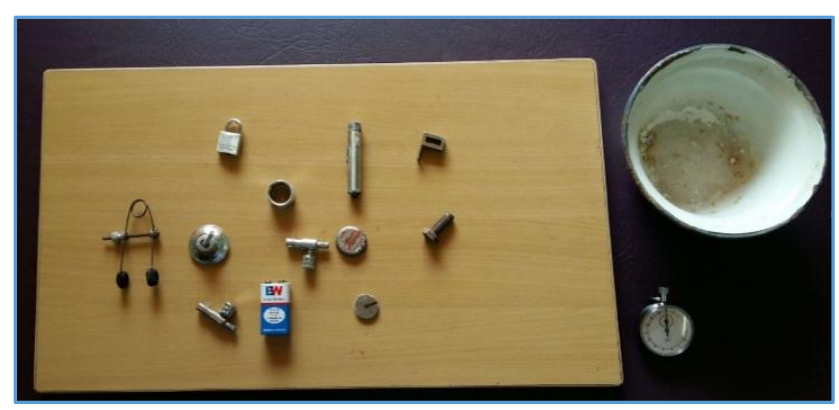

Figure 1

\section{RESULTS}

The study was conducted in 150 medical students of which 86 were female and 64 were male. The data were expressed as mean \pm S.D. and was analysed using student's t-test.
All subjects performed Moberg pickup test faster with their dominant hand as compared to their non-dominant hand both when eyes open and blind folded (Table 1), and the overall mean values with eyes open and when blindfolded were found to be statistically significant.

\begin{tabular}{|c|c|c|}
\hline & Eyes Open & Blindfolded \\
\hline Dominant Hand & $10.30 \pm 0.09$ & $19.13 \pm 0.24$ \\
\hline Non-dominant Hand & $11.21 \pm 0.10$ & $19.86 \pm 0.24$ \\
\hline Standard deviation & 1.31 & 3.02 \\
\hline t Value & 3.69 & 25.08 \\
\hline P value & $<0.001^{*}$ & $<0.001^{*}$ \\
\hline
\end{tabular}

Table 1. Overall Latency (sec) for Dominant and Nondominant Hand with Eyes Open and Blindfolded (n=150)

When compared individually in males and females with eyes open, dominant hand was faster as compared to the nondominant hand and was found to be statistically significant. However, when blindfolded a significant difference was observed in females and the dominant hand was faster than non-dominant hand (Table 2 and 3 ).

\begin{tabular}{|c|c|c|}
\hline & Eyes Open & Blindfolded \\
\hline Dominant Hand & $10.16 \pm 0.15$ & $20.12 \pm 0.46$ \\
\hline Non-dominant Hand & $11.07 \pm 0.18$ & $20.15 \pm 0.44$ \\
\hline Standard Deviation & 1.43 & 3.64 \\
\hline t Value & 4.61 & 0.37 \\
\hline P value & $<0.001^{*}$ & $<0.7$ \\
\hline
\end{tabular}

Table 2. Latency (sec) for Dominant Hand and Non-dominant Hand with Eyes Open and Blindfolded in Males $(n=64)$

\begin{tabular}{|c|c|c|}
\hline & Eyes Open & Blindfolded \\
\hline Dominant Hand & $10.41 \pm 0.11$ & $18.39 \pm 0.23$ \\
\hline Non-dominant Hand & $11.32 \pm 0.12$ & $19.64 \pm 0.25$ \\
\hline Standard Deviation & 1.21 & 2.36 \\
\hline t Value & 49.30 & 33.27 \\
\hline $\mathrm{P}$ value & $<0.001^{*}$ & $<0.001^{*}$ \\
\hline \multicolumn{3}{|c|}{$\begin{array}{l}\text { Table 3. Latency (sec) for Dominant Hand and Non-dominant } \\
\text { Hand with Eyes Open and Blindfolded in Females }(n=86)\end{array}$} \\
\hline
\end{tabular}

Males were found to be faster than females while performing the test using both dominant and non-dominant hand with eyes open and blind folded and the values were found to be highly significant. (Table 4).

\begin{tabular}{|c|c|c|c|c|}
\hline & \multicolumn{2}{|c|}{ Eyes Open } & \multicolumn{2}{|c|}{ Blindfolded } \\
\hline & Dominant Hand & Non-dominant Hand & Dominant Hand & Non-dominant Hand \\
\hline Males & $10.16 \pm 0.44$ & $11.07 \pm 0.51$ & $20.12 \pm 1.30$ & $20.15 \pm 1.59$ \\
\hline Females & $10.41 \pm 0.01$ & $11.32 \pm 0.14$ & $18.39 \pm 0.71$ & $19.64 \pm 0.61$ \\
\hline t Value & 4.39 & 3.78 & 9.57 & 2.43 \\
\hline$P$ value & $<0.001^{*}$ & $<0.001^{*}$ & $<0.001^{*}$ & $<0.01$ \\
\hline & $\begin{array}{l}\text { e 4. Comparative } \\
\text { nd with Eyes Open }\end{array}$ & $\begin{array}{l}\text { s of Latency for Domin } \\
\text { Blindfolded in Males }\end{array}$ & $\begin{array}{l}\text { and and Non-dom } \\
\text { ) and Females ( } n=\end{array}$ & \\
\hline
\end{tabular}

\section{DISCUSSION}

Amongst 150 subjects, one female and one male was left handed and rest all had right hand as their dominant hand. Hemispheric specialisation is related to handedness. Handedness appears to be genetically determined. In $96 \%$ of right-handed individuals, who constitute $91 \%$ of the human population, the left hemisphere is the dominant or categorical hemisphere; and in the remaining $4 \%$, the right hemisphere is dominant.(8) This dominance may probably be due to the difference in the composition of the neuronal network that allows faster specialised functions by the dominant hand. 
In our study, it was observed that students performed the test faster with their dominant hand as compared with their non-dominant hand. This is in conformity with the study conducted earlier.(7)

This could be due to habitual usage of the dominant hand or selective preference of the dominant hand by the brain which caused the individual to perform faster with dominant hand over which they have more control, than non-dominant hand. Some of the cognitive processes and hand eye coordination are better performed by the dominant hand. ${ }^{(9)}$

In our study, students performed the test faster with eyes open than blindfolded in comparison with study conducted by Amirjani et al.(7) This increase in latency with a blindfold could be due to lack of sensory inputs from the visual pathway which reduces hand eye coordination when blindfolded and also due to the additional time taken by the subjects to locate the objects on the wooden platform. Also, since visual cues are absent, the subject solely depends on cutaneous feedback which is essential for gripping objects.

The reduction in latency with eyes open may probably be due to the fact that humans have been gifted with binocular vision. This allows for: (i) Greater increase in the depth perception or the ability to distinguish the distance of the object. (ii) It also allows for stereopsis or the ability to see in three dimensions that gives a person with binocular vision, far greater ability to judge relative distances when objects are nearby than a person with monocular vision. (iii) Binocular vision also compensates for the presence of blind spots in our eyes and widens field of vision. $(8,9)$

Males performed the test faster than females using both dominant and non-dominant hand with eyes open and with blindfolded. This is in contrast to the study conducted by Amirjani et al. Studies also have shown that there is a significant difference in the motor and mental development of males and females.(10) Males are found to surpass females in the development of gross and fine motor skills. Studies conducted by Valtroslav et al suggests that the males are superior than females in coordination and they have significantly better results in motor tests for estimation of explosive strength and functional coordination of primary motor abilities.(11)

Also, studies conducted by Coetzee \& Du Plessis in the past showed that males had a slightly higher correlation with visual-motor integration and visual perception than females. The significant difference observed in our study may be due to the fact that males usually start to socialise earlier in life compared to females, also visual-motor skills in them are developed better due to the nature of tasks they face at home and elsewhere.(11)

It is seen that males have better spatial coordination and sense of direction compared to females, thereby giving them an edge in interpreting three-dimensional objects and better hand-eye coordination, thus a precise control of large muscle movement. Reasons for this could be due to testosterone hormone which in prenatal development, causes to organise the brain in either the male or female circuitry. The male develops in the presence of high testosterone hormone, which helps in developing the proper sexual organs and also causes organisation of the brain.(8) We know that in olden times, females remained with their children at home while males go out for livelihood. This must have probably caused the brain to develop differently in males and females.

\section{CONCLUSION}

Moberg pickup test being simple, convenient and cheaper can widely be applied to assess hand coordination with respect to age and gender of individual and could be also used as an assessment tool for recovery of hand functions following injury.

\section{REFERENCES}

[1] John BM, Didier P. Guideline for hand hygiene in health care setting. 2002.

[2] Collins DF, Prochazka A. Movement illusions evoked by ensemble cutaneous input from the dorsum of the human hand. J Physiol 1996;496(Pt 3):857-71. http://jp.physoc.org/content/496/Pt_3/857.abstract? ijkey $=8612191 \mathrm{~b} 71 \mathrm{f} 72 \mathrm{a} 47 \mathrm{dfeb} 993 \mathrm{cdec} 88 \mathrm{a} 464344217$ f\&keytype2=tf_ipsecsha

[3] Jenmalm P, Dahlstedt S, Johansson RS. Visual and tactile information about object-curvature control fingertip forces and grasp kinematics in human dexterous manipulation. J Neurophysiol 2000;84(6):2984-97.

[4] Ghez C, Sainburg R. Proprioceptive control of inter joint coordination. Can J Phyiol Pharmacol 1995;73(2):273-84.

[5] Edin BB, Westling G, Johansson RS. Independent control of human finger-tip forces at individual digits during precision lifting. J Physiol 1992;450(1):547-64. http://www.pubmedcentral.nih.gov/articlerender.fcgi ?artid=1176137\%7B\&\%7Dtool=pmcentrez\%7B\&\%7 Drendertype=abstract\%5Cnhttp://www.pubmedcent ral.nih.gov/articlerender.fcgi?artid=1176137\&tool=p mcentrez\&rendertype=abstract

[6] Moberg E. Objective methods for determining the functional value of sensibility in the hand. J Bone Joint Surg Br 1958;40-B(3):454-76.

[7] Amirjani N, Ashworth NL, Gordon T, et al. Normative values and the effects of age, gender, and handedness on the Moberg Pick-Up Test. Muscle and Nerve 2007;35(6):788-92.

[8] Barrett KE, Barman SM, Boitano S, et al. Ganong's review of medical physiology. 25th edn. McGraw Hill 2016.

[9] Guyton AC, Hall JE. Textbook of medical physiology. $13^{\text {th }}$ edn. Philadelphia, PA: Elsevier 2016.

[10] Singh CK, Dhanda B, Shanwal P. Gender difference in motor and mental development in children: an impact of stimulating activities. Anthropologist 2010;12(2):153-4.

[11] Vatroslav H, Ivan P, Marijana H. The Relationship between motor abilities, physical activity and gender in preschool children. Gymn Sci J Educ Sport Heal 2014;15(2):89-93. http://search.ebscohost.com/login.aspx?direct=true \& $\mathrm{db}=\mathrm{s} 3 \mathrm{~h} \& \mathrm{AN}=101154695$ \&lang=pt-br\&site=ehost-live 